Promethean hero. His goal is not to give all the historical details of the epic; rather, it is to explore the questions surrounding the evolution, on a late branch of the primate phylogenetic tree, of this apparently improbable freak group once thought to be of divine origin: a bipedal sweaty ape afflicted with a costly large brain. What are human beings? Why Africa? When did we become humans? Why did humans evolve?

Foley offers clear and often original answers to crucial questions. His perspective is definitely Darwinian and sometimes (refreshingly) non-politically correct. Drawing on biology, palaeontology, ecology and ethology, he explains how small causes scattered over vast geological times have produced great effects. A number of conventional ideas are usefully broken and the result is really fascinating. Anyone interested in evolution must read this book.

Our origins are definitely tropical. And to varying degrees, virtually all palaeoanthropologists now support the notion of humans having an African origin and evolutionary continuity on that continent. Africa was until recently the core demographic and selective environment of hominids. Strongly opposing models mainly concern areas that remained marginal for most of hominid evolution. Indeed, human palaeontology was born outside the vast garden of Eden, in Europe where archaic humans evolved away from the mainstream and were finally submerged. But other marginal areas are either terra incognita or do not fit so easily into a simplistic 'replacement' model.

In fact, the Far Eastern evidence is relatively little commented on in these three books. How many 'Out of Africa' events do we need to interpret the Asian archaic hominids? How much parallel evolution can we see in these remote populations? Did they reach the status of a distinct species of hominid? If not, could there have been gene flow between different waves of human populations invading Asia? Enigmas still persist inside and outside the Garden of Eden.

Jean-Jacques Hublin is at the CNRS Laboratoire d'Anthropologie, Museé de l'Homme, Place du Trocadero, 75116 Paris, France.

\section{Classic reissue}

Adaptation and Natural Selection: $A$ Critique of Some Current Evolutionary Thought by George $C$. Williams. This hugely influential book, first published in 1966, combines original insight with a hard-headed defence of Darwinian selection. The author, one of the leading US evolutionary biologist, provides a new introduction.

\title{
Now that's what you call chamber music
}

MANY readers will have heard a version of the curious auditory illusion, deliberately constructed, whereby a sequence of musical notes seems continually to ascend in pitch. It is, in a loose sense, an aural analogue of Escher's twodimensional lithograph in which monks endlessly ascend (and others endlessly descend) the stairs around the top of their illusory monastery. The aural illusion has various relatives, all of which I find amusing. But music they are not.

By contrast, the 'compositions' by Zach Davids on the new compact disc Heartsongs: Musical Mappings of the Heartbeat are definitely musical. Yet they are derived, in a direct way, from

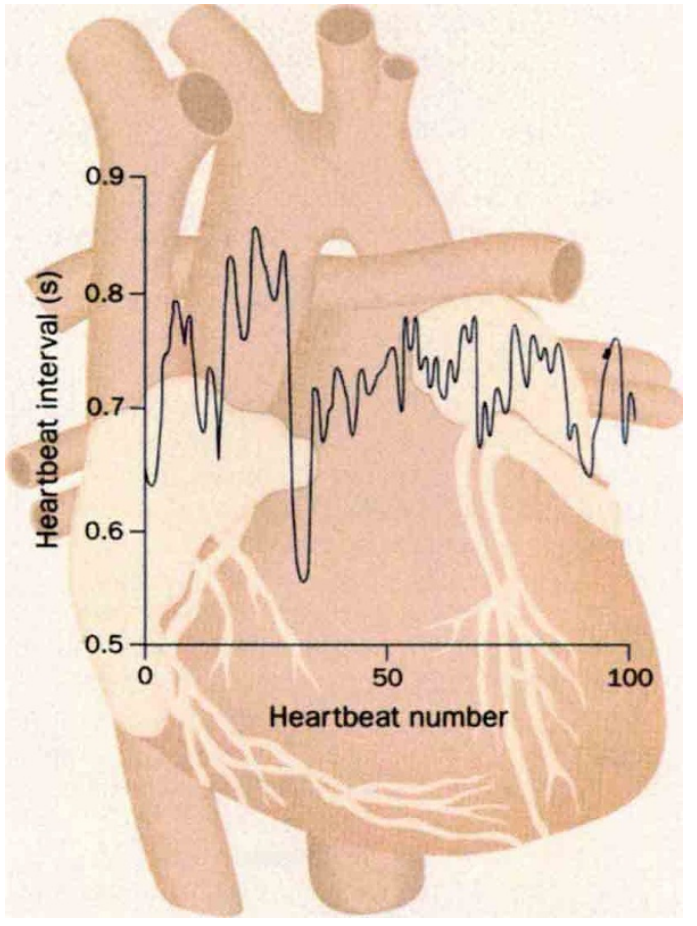

Heartbeat fluctuations of a healthy person

digital tape recordings of actual heartbeats from 15 people at Harvard Medical School's Beth Israel Hospital.

The CD is published by Ivory Moon Recordings (22 Rutgers Road, Wellesley, Massachussetts 02181, USA; CD 7 88897-68002-3) and arises from a project developed as part of a major exhibit at the Boston Museum of Science (which opened in December last year) entitled "The Dance of Chance: Growing Order out of Randomness". It comes with explanatory notes written by Ary Goldberger and Zach Golberger (Davids's nonprofessional name), C.-K. Peng and Paul Trunfio, who are all at Harvard Medical School and Boston University.

Beginning with electrocardiogram data, the authors measured the precise intervals between heartbeats to obtain a time series of changes in heart rate. Our heartbeats in fact have a great deal of subtle variability from one beat to the next, caused by the normal workings of the involuntary nervous system. In the authors' words: "the normal heartbeat, therefore, does not follow a metronometic or march-like beat - surprisingly, it has a dance-like plasticity and variability".

The next step was to convert the time series of intervals between heartbeats into integers on a scale of 1 to 18 . (This process requires smoothing: 330 integers were obtained for each dataset of 100,000 heartbeats; that is, the average was taken over successive runs of 300 beats.) The last step was to map the numbers onto a musical scale, specifically the diatonic musical scale.

In this way, the sequences of integers generated the melody. Changes in pitch were proportional to the changes in heart rate. So much for the mechanics. The composer (Davids) was then "free to choose the rhythm and harmonic accompaniment for each melody", say the authors. "However, the underlying melodic line for each piece remains true to the original heartbeat time series." This leaves me in a bit of doubt about exactly how much of what one hears is undiluted "heartsong".

What is clear, however, is that the result is musically pleasing, at least to my unsophisticated ear. And, like Goldberger and colleagues, I think this raises interesting questions.

We could equally have ended up with boring sameness, or even dissonant jangle. The authors speculate that musical composition may involve, to some degree, "the recreation by the mind of the body's own naturally complex rhythms and frequencies. Perhaps what the ear and the brain perceive as pleasing or interesting are variations in pitch that resonate with or replicate the body's own complex (fractal) variability and scaling."

This is probably all a bit overheated, but the fact remains that this music largely mechanically produced - is intriguing to listen to. Buy the $C D$ and form your own view.

Robert M. May is Chief Scientific Adviser to the UK government, on leave from the Department of Zoology, University of Oxford, Oxford OX1 3PS, UK. 